\title{
Thrombocytosis as a Predictor of Serious Bacterial Infection
}

\author{
Neelam Marwaha \\ Professor and Head, Department of Transfusion Medicine, Postgraduate Institute of Medical Education and Research, \\ Chandigarh,India.neelam2918@yahoo.com
}

$\mathrm{F}$ ever is one of the most common conditions requiring the attention of the pediatrician. The evaluation of an infant with febrile illness and no obvious focus of infection is a challenging task and can be expensive, timeconsuming and invasive. The general condition of the infant can be deceptive and does not assist reliably in clinical differentiation of a low risk versus high risk bacterial infection(1). This is compounded by the fact that no single laboratory test has been shown to identify infants with serious bacterial infection (SBI). Laboratory markers which have been used to predict SBI include raised white blood cell (WBC) counts, C-reactive protein (CRP), procalcitonin (PCT) and even interleukin-6 levels(2). WBC count, though easily available and used widely as a predictor of SBI, by itself, does not compare well with relatively more recent markers like CRP and PCT.

Availability of automated hematology analyzers gives results of platelet counts as a part of the routine hematology work-up, with a dependable degree of accuracy. Thrombocytosis or increase in platelet counts $>400,000 / \mu \mathrm{L}$ have been documented in $3 \%$ to $15 \%$ of pediatric patients(3). Thrombocytosis in this age group is invariably due to an underlying cause such as acute infection, chronic inflammation, childhood malignancies, iron deficiency anemia and chronic hemolytic states. Primary or essential thrombocythemia is extremely rare. Infections of the respiratory, urinary and gastrointestinal tract and the bones and meninges are the most common causes of reactive thrombocytosis. Platelet counts in most cases range between $>400,000 / \mu \mathrm{L}$ to $700,000 / \mu \mathrm{L}$, but in $6-8 \%$ of children may range between $>700,000 / \mu \mathrm{L}$ to $1,000,000 / \mu \mathrm{L}$ and in $2-3 \%$ patients, the counts can be markedly elevated $(>1,000,000 /$ $\mu \mathrm{L})$. Higher counts are more common in neonates and infants(4). However, the platelet count has not been evaluated as a predictor of SBI among febrile infants.

In this issue of Indian Pediatrics, Fouzas and colleagues(5) have estimated the incidence of reactive thrombocytosis among febrile infants and assessed the utility of platelet count as a potential predictor of SBI in these patients. The study is a retrospective analysis of case-records of 408 infants aged 29-89 days with fever without a focus of infection. All patients had sepsis evaluation including blood counts, culture, urine microscopy and culture and CRP estimation. Chest radiographs, stool culture and lumbar puncture for cerebrospinal fluid examination had been performed when indicated. Thus the results of standard investigations of sepsis were available. SBI was documented in 103 $(25.2 \%)$ of the infants. The mean platelet count in SBI infants was observed to be significantly higher than non-SBI infants. However, no single cut-off value could be ascertained due to overlap of platelet counts between the two groups. A discriminatory threshold of $>450,000 / \mu \mathrm{L}$ platelet count as a single parameter had comparable specificity and sensitivity with other laboratory tests. Taken singly it offered no advantage over existing markers of SBI. Addition of platelet count $>450,000 / \mu \mathrm{L}$ to a combination of other predictive parameters i.e. $\mathrm{WBC} \geq 15,000 / \mu \mathrm{L}$, pyuria $\geq 10 \mathrm{WBC} / \mathrm{hpf}$ and $\mathrm{CRP} \geq 2 \mathrm{mg} / \mathrm{dL}$ significantly improved sensitivity. 
The study provides valuable data where addition of a routine hematology parameter like platelet count to the sepsis screen results in better discrimination between SBI and non-SBI infants. This assumes significance in both the emergency services where quick turnaround time of laboratory tests is essential and in pediatric care in developing countries where cost constraints do not readily permit inclusion of expensive investigative tools.

Funding: None.

Competing interests: None stated.

\section{REFERENCES}

1. Baker MD, Avner JR, Bell LM. Failure of infant observation scales in detecting serious illness in febrile, 4- to 8-week-old infants. Pediatrics 1990; 85: 1040-1043.

2. Hsiao AL, Baker MD. Fever in the new millennium: a review of recent studies of markers of serious bacterial infection in febrile children. Curr Opin Pediatr 2005; 17: 56-61.

3. Mantadakis E, Tsalkidis A, Chatzimichael. A: Thrombocytosis in childhood. Indian Pediatr 2008; 45: 669-677.

4. Dame C, Sutor AH. Primary and secondary thrombocytosis in childhood. Br J Haematol 2005; 129: 165-177.

5. Fouzas S, Mantagou L, Skylogianni E, Varvarigou, A. Reactive thrombocytosis in febrile young infants with serious bacterial infection. Indian Pediatr 2010; 47: 937-943. 